\title{
Interface resistances in heat and moisture transport: semi-scale experimental analysis
}

\author{
Z. Pavlík, J. Mihulka, J. Žumár, M. Pavlíková \& R. Černý \\ Department of Materials Engineering and Chemistry, \\ Faculty of Civil Engineering, Czech Technical University in Prague, \\ Czech Republic
}

\begin{abstract}
A sophisticated semi-scale system which allows experimental simulation of heat and moisture transport in building structures is employed for analyzing heat and moisture transfer across interfaces in stone masonry formed by argillite walling blocks and lime-pozzolana mortar. The dimensions of investigated structure are close to a real wall but the measuring accuracy is the same as in a laboratory experiment. Combined relative humidity and temperature mini-sensors are utilized in continuous long-term monitoring. Measured temperature and relative humidity profiles provide information on the properties of the interface between the walling material and mortar which makes possible to identify the interface permeability. This parameter can then be used in computational models of heat and moisture transport in masonry which adds to the accuracy of model predictions.
\end{abstract}

Keywords: heat and moisture transport, interface resistances, semi-scale experiment, stone masonry, argillite, lime-pozzolana mortar.

\section{Introduction}

Computational modelling of coupled moisture and heat transport represents an effective tool for prediction of behaviour of building structures exposed to climatic load. For reliability of computational analysis, two requirements must be met. At first, mathematical-physical model describing the coupled moisture and heat transport must be formulated. From the theoretical point of view, this model should be sufficiently sophisticated and complex, and should take into account all the external and internal effects that affect the moisture and heat 
transport. Typical example of such complex models represents for instance hybrid model developed by Grunewald $[1,2]$ that takes into account both diffusion and convection effects on moisture and heat transport. Although these models describe the physical reality of coupled moisture and transport in sophisticated way, their practical application for hygrothermal analysis of building structures is often limited by the accuracy and availability of input parameters that represent the second limiting requirement of computational modelling.

There are two types of input parameters which have to be known in advance for precise computational analysis. The first are initial and boundary conditions. In case of analysis of existing structure, for example by reason of intended reconstruction, initial conditions can be determined using on site analysis of moisture and temperature fields in the studied structure. Boundary conditions are of two types. The first of them are meteorological data for temperatures, relative humidities, rainfall and solar radiation, possibly also concentration of acidforming gases in the atmosphere. This type of data can be obtained from meteorologists in the form of so-called TRY (Test Reference Year) data which present certain average values over a sufficiently long time period. The second type of boundary conditions involves water content in the underground soil close to the studied building. These data can be obtained again by on site analysis [3].

The second type of input parameters are hygric and thermal transport and storage parameters of the materials of the structure which appear in water and heat mass balance equations implemented in the models. In case of study of coupled moisture and heat transport, these parameters include moisture diffusivity and diffusion coefficient of water vapour, sorption isotherms and water retention curves that can be optionally expressed as moisture potential curves, thermal conductivity and specific heat capacity. Within the application of computational modelling, one must take into account that all above given parameters are functions of both temperature and moisture. Therefore, there is a need to determine these parameters in dependence on moisture and temperature changes what is highly time-consuming, and for some types of materials practically unfeasible. On that account, one must assume diversion of computational simulations from reality, and the computer codes must be calibrated and validated using experimentally measured moisture and moisture profiles. Only after this validation is done, the computational modelling can be applied with sufficient accuracy.

Specific problem for validation of computational codes solving the coupled moisture and heat transport represent composite materials and structures, where interface resistances crucially affect the reliability of modelling. Most classical models of heat and moisture transport in porous materials do not deal with moisture transport across interfaces between two porous materials in an explicit way. In practical calculations, the simplest solution is commonly used. It is assumed that there is ideal contact between the two materials, which means the equality of temperatures and moistures, taken as limits on the right and the left to the interface. However, this requirement can sometimes lead to dramatic but unclear moisture profiles in the regions close to the interface, particularly if the 
bordering materials have considerably different transfer coefficients. Therefore, the condition that the macroscopic capillary pressure must be continuous across the interface is adopted in more sophisticated models, implying an ideal hydraulic contact. Then, at the interface between two different materials a moisture jump across the interface appears, which can be theoretically determined on the basis of the measured water accumulation functions of both materials. In the case a non-ideal hydraulic contact is formed on the interface due to the different pore size distributions of the adjacent porous materials, a jump of capillary pressure along the interface characterized by the interface permeability can appear. Typical example of non-ideal hydraulic contact of two materials represent masonry, where the water transport properties of walling blocks and mortar are different due to the differences in their pore size distribution. In order to decide which of the particular transport models is realistic for a specific interface, an experimental analysis is required.

On that account, an experimental analysis of temperature and moisture transport across the material interfaces in stone masonry is studied in this paper to reveal the interface effects on the moisture and temperature distribution.

\section{Semi-scale experiments}

The semi-scale experiments are presently very popular in verification and calibration of HAM (Heat, Air, and Moisture transport) models since they allow monitoring of hygrothermal changes in the studied structures in more detailed way and the certain specific cases can be studied what is not very common in the case of full test house measurement $[4,5]$.

The semi-scale measuring system for determination of temperature and moisture fields is designed in such a way that it simulates conditions, which are as close as possible to the real conditions on building site, but it still maintains its laboratory character, so that the expenses are kept considerably lower compared to a real test house. Also the accuracy of applied measuring methods for moisture content and temperature measurement is much higher compared to insitu measurements [6].

\section{Experimental}

Within the performed experiments, the moisture and heat transport in the fragment of argillite wall was studied. Two separate semi-scale experiments were designed and performed in order to evaluate the effect of interface resistances on the transition between the argillite walling blocks and mortar. Within the first experiment, the heat transport was simulated, whereas the relative humidity was maintained on constant level. In the second experimental arrangement, relative humidity transport was monitored at constant temperature conditions.

\subsection{Studied masonry and inbuilt materials}

Two materials typical for historical masonry in Central European territory were used. The researched fragment of the stone masonry consisted of argillite blocks 
and lime mortar with pozzolana admixture based on calcined kaoline mixed with milled mudstone. The composition of applied mortar is given in Table 1.

Table 1: Composition of applied plaster.

\begin{tabular}{|c|c|c|c|}
\hline $\begin{array}{c}\text { lime hydrate } \\
(\mathrm{kg})\end{array}$ & $\begin{array}{c}\text { pozzolana } \\
(\mathrm{kg})\end{array}$ & $\begin{array}{c}\text { sand } 0-4 \mathrm{~mm} \\
(\mathrm{~kg})\end{array}$ & $\begin{array}{c}\text { w/d ratio } \\
(-)\end{array}$ \\
\hline 200 & 50 & 750 & 0.23 \\
\hline
\end{tabular}

In Table 1, w/d represents the water/dry substance ratio. Lime hydrate is product of lime kiln Čertovy schody, Inc., Czech Republic, whereas the silicious sand is coming from sand-pit Hlavačov, Czech Republic. The applied argillite is coming from quarry Džbán, Czech Republic. It is highly heterogeneous fine-pore material with anisotropic structure. It is characteristic by diversity in composition, whereas its main constituents are illite, kaolin, minerals of $\mathrm{SiO}_{2}$, spar and mica.

Basic physical properties of both masonry materials are given in Table 2.

Table 2: $\quad$ Basic properties of masonry materials.

\begin{tabular}{|c|c|c|c|}
\hline material & $\begin{array}{c}\text { bulk density } \\
\left(\mathrm{kg} / \mathrm{m}^{3}\right)\end{array}$ & $\begin{array}{c}\text { matrix density } \\
\left(\mathrm{kg} / \mathrm{m}^{3}\right)\end{array}$ & $\begin{array}{c}\text { total open porosity } \\
(-)\end{array}$ \\
\hline mortar & 1688 & 2560 & 0.34 \\
\hline argillite & 1353 & 2235 & 0.39 \\
\hline
\end{tabular}

\subsection{Experimental arrangement, measuring technology}

For simulation of moisture and heat transport in the investigated structure, a semi-scale system was used. The device (Figure 1) consists of two climatic chambers for simulation of climatic conditions, connecting tunnel, where the investigated structure is placed, and commercial devices for continuous monitoring of field variables as relative humidity, temperature, liquid moisture content, salinity, heat flux, etc. It is also equipped with optional sprinkling device for rainfall simulation.

In the presented experiments, monitoring of relative humidity and temperature changes in the specific places of studied structure was done. For this purpose, sophisticated technique from Ahlborn was used. The accuracy of particular sensors was as follows: $\pm 2 \%$ for capacitive relative humidity sensors applicable in the range of humidities $5-98 \%$, for temperature sensors $\pm 0.4^{\circ} \mathrm{C}$ in the temperature range from $-20^{\circ} \mathrm{C}$ to $0^{\circ} \mathrm{C}$ and $\pm 0.1^{\circ} \mathrm{C}$ in the range from $0^{\circ} \mathrm{C}$ to $70{ }^{\circ} \mathrm{C}$. For testing the tightness of climatic chamber system, the anemometers for air flow velocity measurements were used. The whole measuring system was operated by a computer, including the climatic data entry into the particular climatic chambers. The details on the system including the measuring technology and sensors calibration can be found in [6].

The measuring process can be divided into several basic phases: walling the investigated structure, sensors' installation into the built wall fragment, sample 


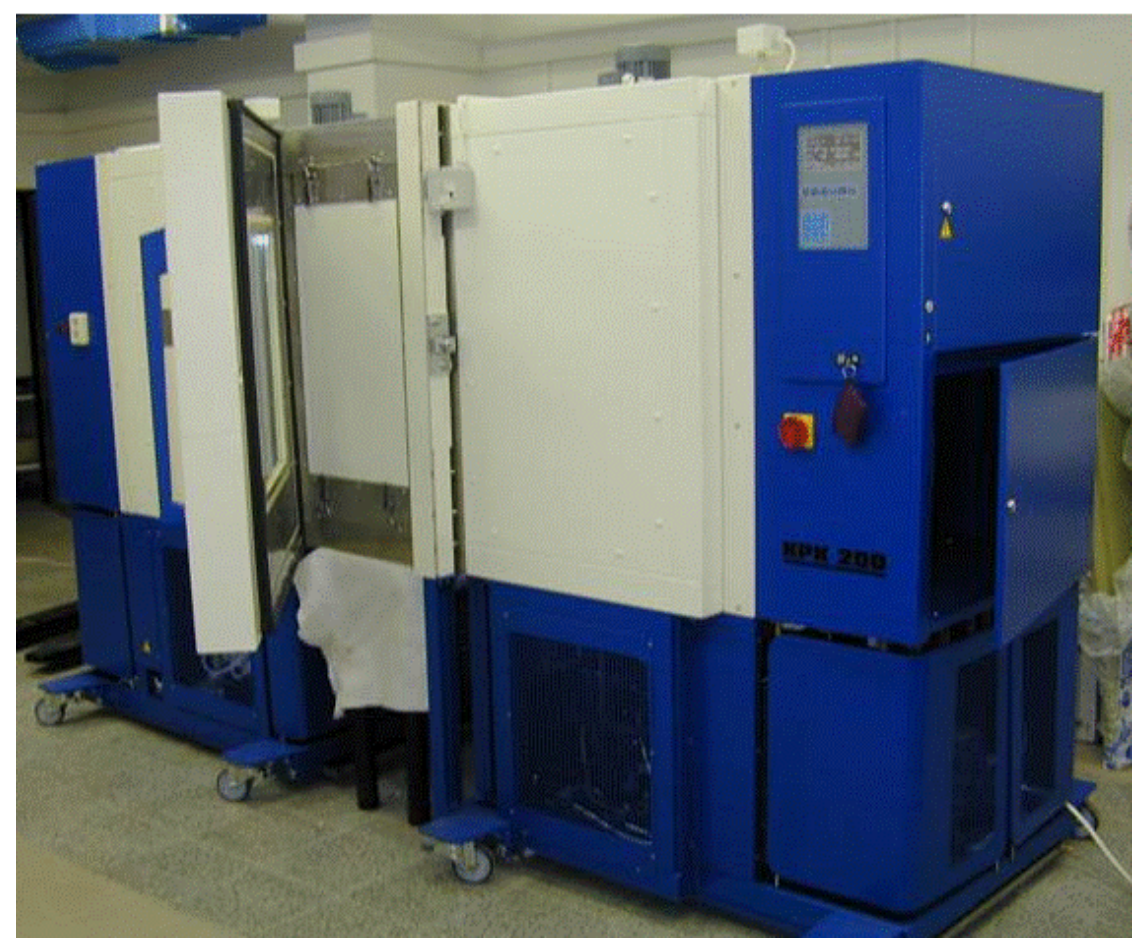

Figure 1: Climatic chamber system for semi-scale experiments.

positioning into the tunnel between the climatic chambers, climatic loading simulation, temperature and relative humidity monitoring, data evaluation. The walling of the studied structure was done in the standard way using dry mortar mix and wet technological process. The sensors for monitoring temperature and relative humidity were placed to the investigated construction to beforehand bored holes. The upper part of the bore opening was closed by silicon sealing. Placing of the sensors was done regarding to the study of interface moisture and heat transport (Figure 2).

For a proper setting of climatic conditions, it was necessary to achieve nearsteady-state conditions in the studied wall. Therefore, there was necessary to dry freshly built wall to remove technological water. The drying was done at $50^{\circ} \mathrm{C}$ and $10 \%$ of relative humidity for one month.

After that, the first experiment simulating the heat transport at constant moisture conditions was started. On one side of the studied wall, constant temperature of $-9.5^{\circ} \mathrm{C}$ was maintained, whereas on the other side of the masonry fragment, constant temperature of $25^{\circ} \mathrm{C}$ was simulated. The relative humidity varied during the experiment in the range of $\pm 10 \%$, typically between 40 and $50 \%$ in respect to performance of climatic chambers. Duration of the first experiment was 84 days. 


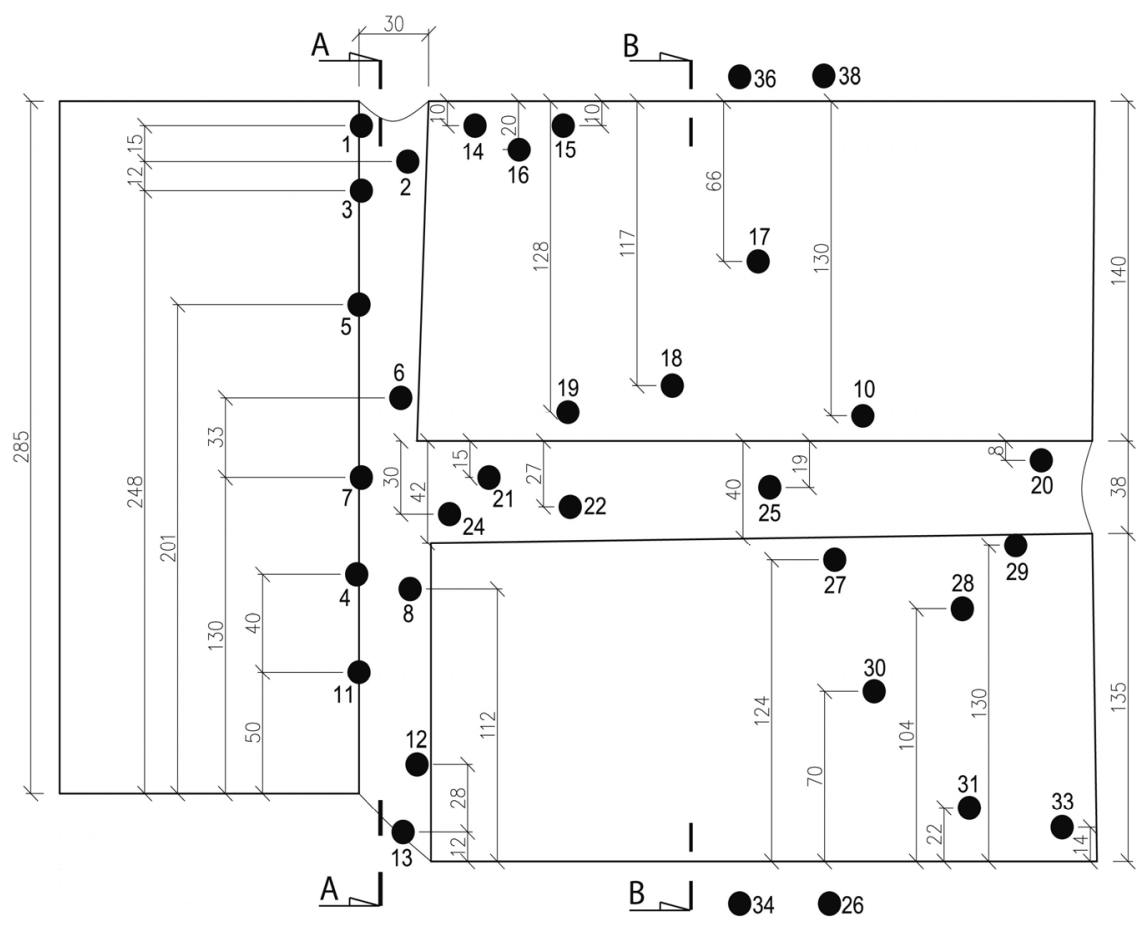

Figure 2: $\quad$ Sensors' positioning and wall arrangement (dimensions in $\mathrm{mm}$ ).

The second experiment was designed to simulate gaseous moisture transport without temperature effects. Also in this case, the climatic chambers' parameters were limiting factor. On one side of the wall, relative humidity of $45 \%$ was simulated, whereas on the opposite wall side, $95 \%$ was reached. The temperature varied within the range of 25 to $28^{\circ} \mathrm{C}$. Duration of this experiment was 81 days.

\section{Results and discussion}

The temperature profiles measured in the first semi-scale experiment are shown in Figures 3-6. The results are presented in two cross sections (A-A, B-B), according to the scheme in Figure 2.

The measured temperature profiles in Figures 3-6 are more or less linear. This indicates that steady state heat transport was reached. We can also observe the expected jumps in temperatures at the contacts of measured wall with ambient environment. They are caused by thermal resistances between the material surface and ambient air. The thermal resistances between the argillite blocks and mortar are manifested as well. The effects of interface resistances are not so distinct as the surface resistances as solid-solid heat transfer can be generally realized in a more ideal way than solid-gas transfer. Nevertheless, their significance is perceptible. 


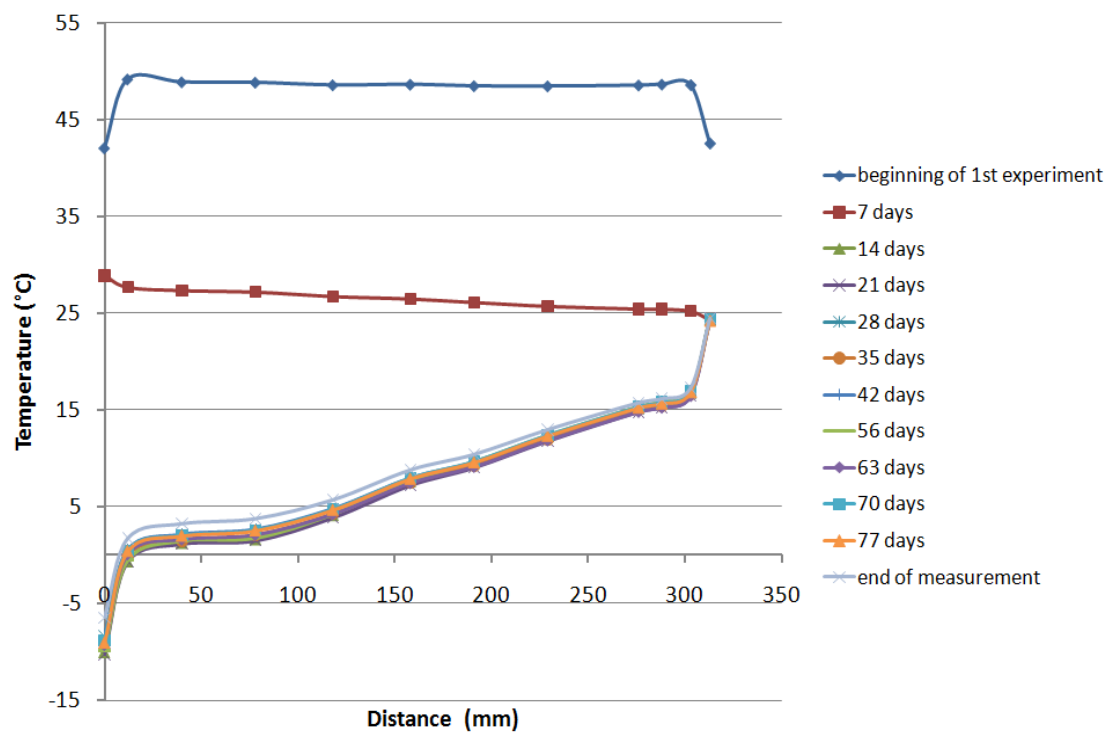

Figure 3: Temperature profiles in cross section A-A (first experiment).

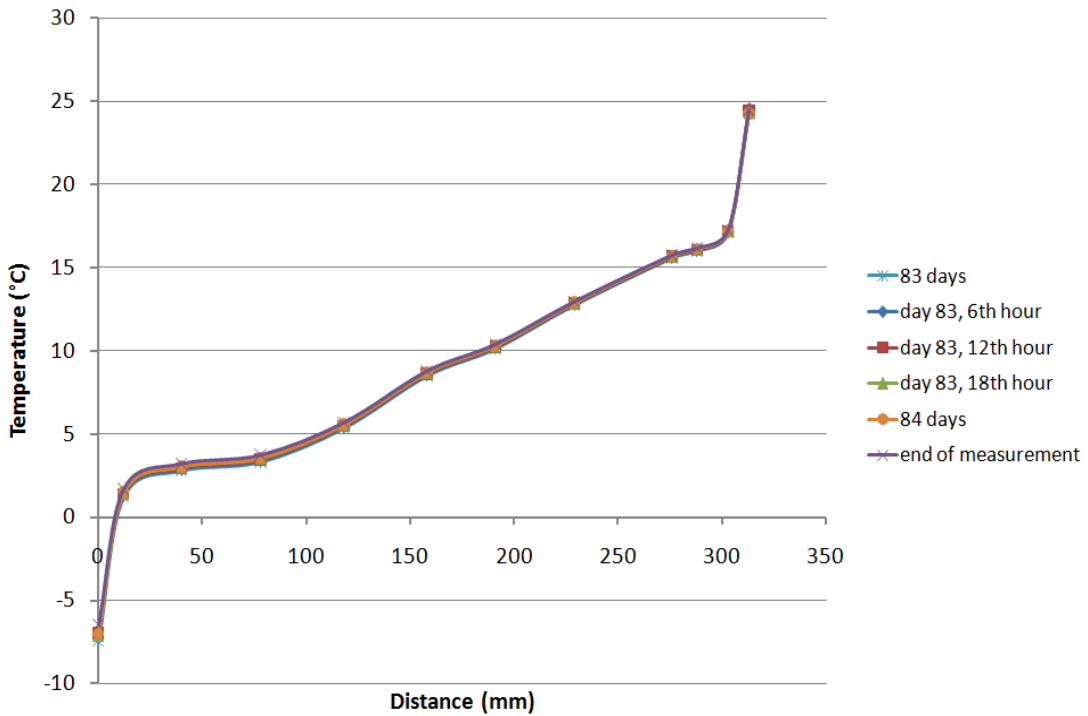

Figure 4: Temperature profiles in cross section A-A (end of the first experiment). 
206 Materials Characterisation V

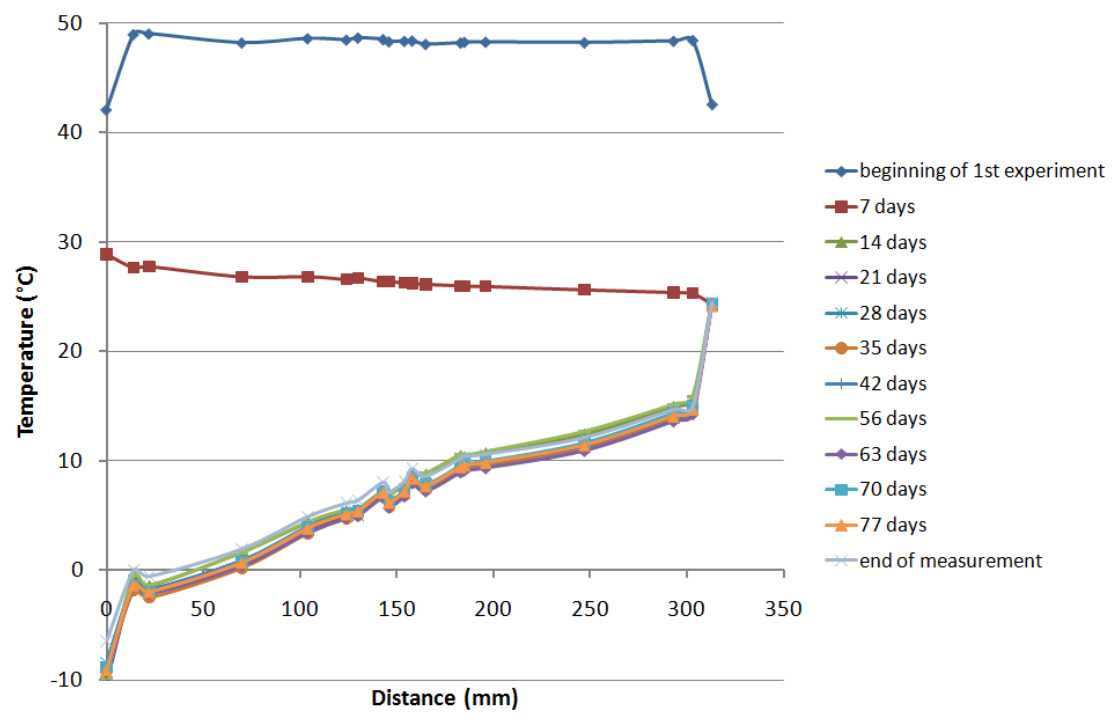

Figure 5: Temperature profiles in cross section B-B (first experiment).

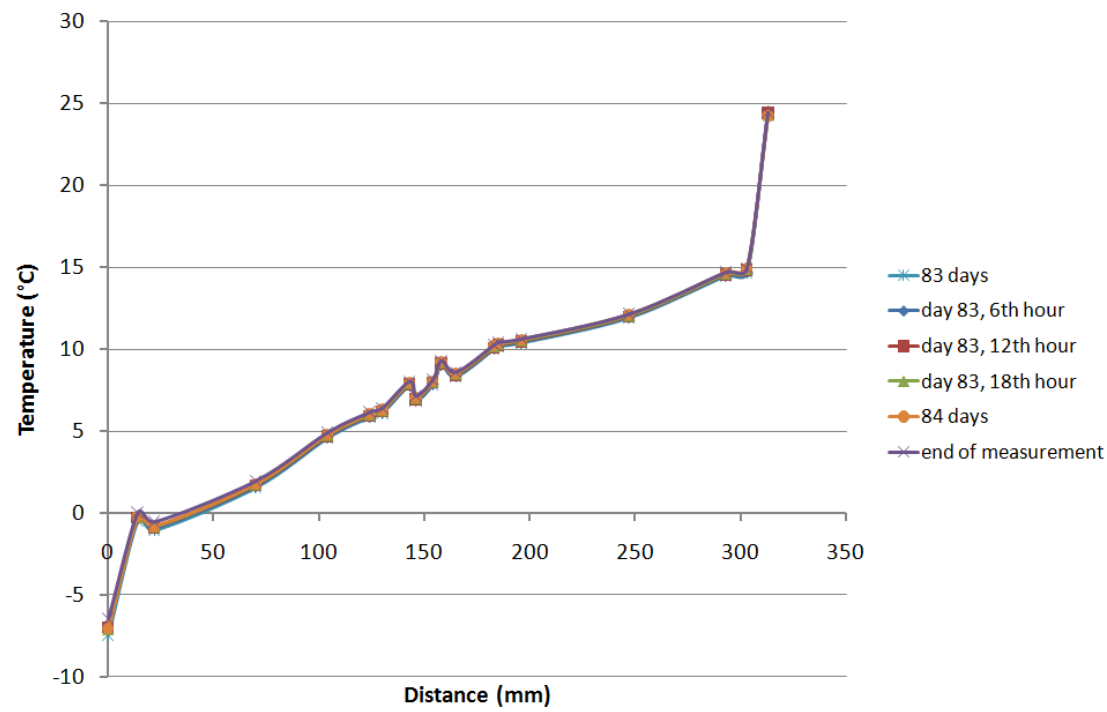

Figure 6: Temperature profiles in cross section B-B (end of the first experiment).

The relative profiles measured in the second semi-scale experiment are shown in Figures 7 and 8. 


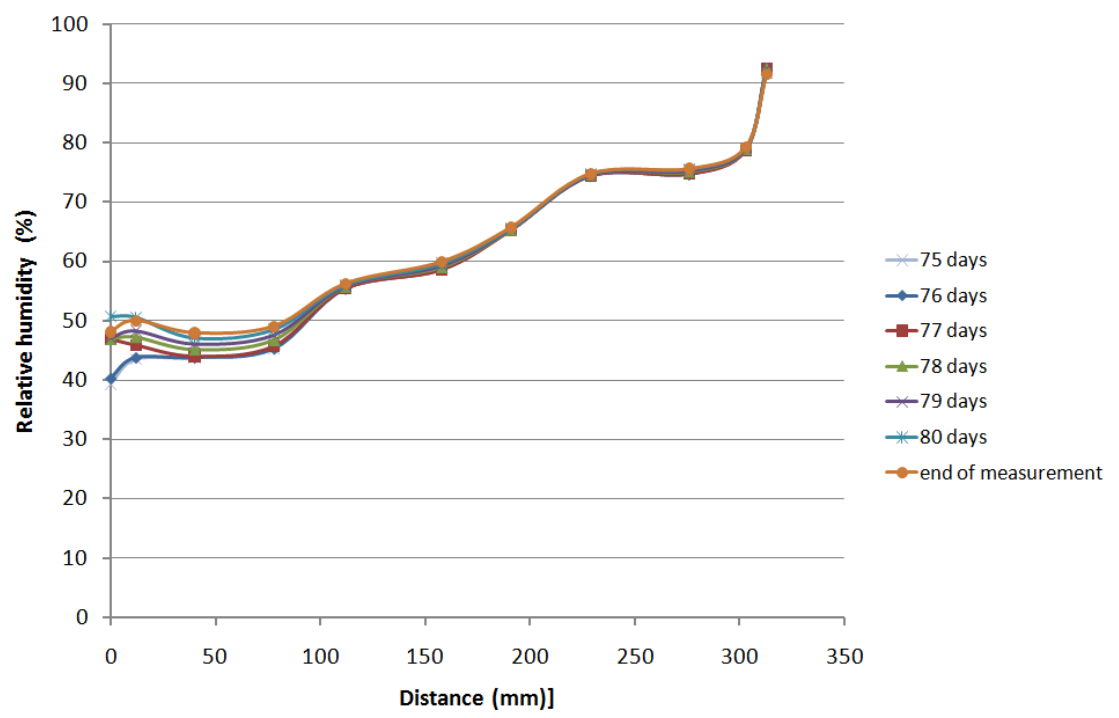

Figure 7: Relative humidity profiles in cross section A-A (second experiment).

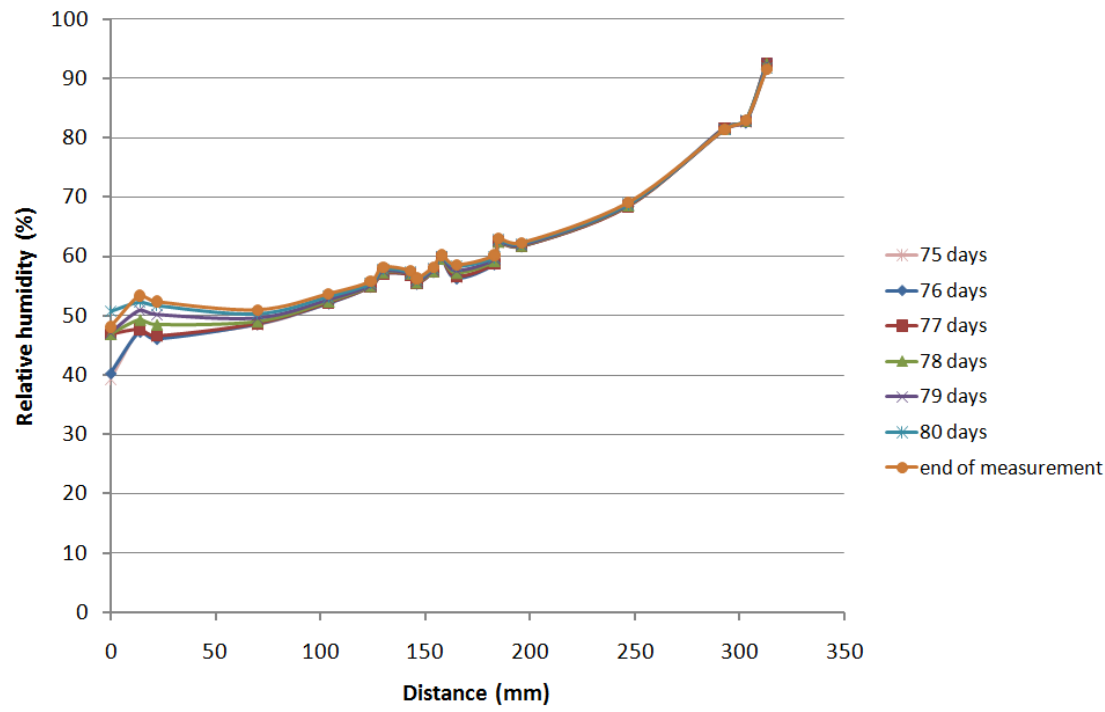

Figure 8: Relative humidity profiles in cross section B-B (second experiment). 
Apparently, in case of simulation of water vapour transport, similar features as in heat transport simulation are observed. The experimental relative humidity profiles reveal significant effects of interface resistances on gaseous moisture transport at the contact of argillite blocks and mortar. The surface resistances remarkably affect the water vapour distribution in the studied masonry as well. The steep parts of relative humidity profiles are highly important for calibration and validation of HAM models of transport phenomena in multilayered systems.

For demonstration of temperature conditions within the water vapour transport simulation, Figure 9 is introduced. Clearly, the effect of interface resistances in the stone-mortar-stone transition zone and surface resistances can be observed even in the case of low temperature differences on opposite wall sides.

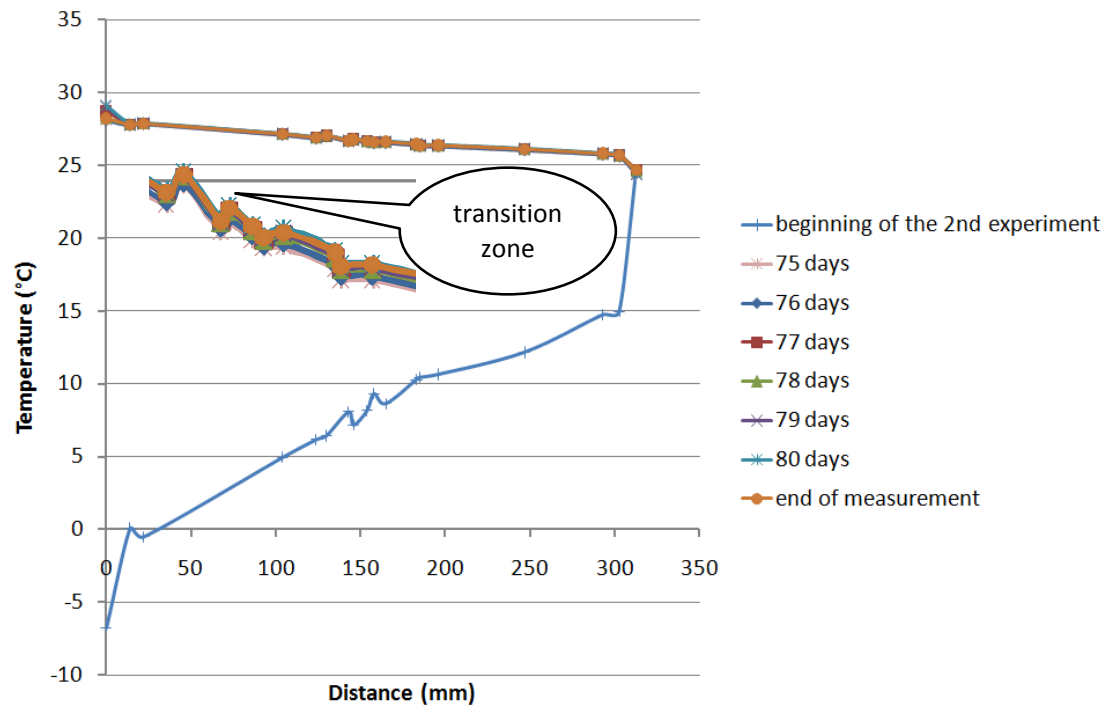

Figure 9: Temperature distribution in cross section B-B (second experiment).

\section{Conclusions}

Experimental investigation of water vapour and heat transport across the interfaces in stone masonry was done in the conditions of 1-D semi-scale experiment. The climatic loading of the studied structure was chosen in such a way that water vapour transport under isothermal conditions and heat transport at constant relative humidity were simulated. The data obtained in both experiments confirmed the significant effect of both interface and surface resistances on water vapour and heat propagation, thus the necessity to include these effects in computational modelling of coupled moisture and heat transport.

On the basis of measured data, determination of heat and water vapour resistances between particular materials' layers is possible using methods of 
inverse analysis. Also, the surface resistances on the contact of studied building structure with ambient air can be accessed. In this way, the results can contribute to higher accuracy of future computational modelling. Neglecting the behaviour of the transition zone between the particular materials forming stone masonry structures, on the other hand, may lead to possible improper design of renovation or construction solutions and subsequent material and structural damage.

\section{Acknowledgement}

This research has been supported by the Czech Ministry of Education, Youth and Sports, under project No MSM 6840770031.

\section{References}

[1] Grunewald, J., Diffusiver und konvektiver Stoff- und Energietransport in kapillarporösen Baustoffen, Ph.D. Thesis, TU Dresden, Dresden, 1997.

[2] Černý, R. \& Rovnaníková, P., Transport Processes in Concrete, 1st ed., Spon Press: London, 547 pp., 2002.

[3] Pavlík, Z., Michálek, P., Pavlíková, M., Kopecká, I., Maxová, I. \& Černý, R., Water and Salt Transport and Storage Properties of Mšené Sandstone. Construction and Building Materials, 22(22), pp. 1736-1748, 2008.

[4] Krus, M., Rösler, D. \& Sedlbauer, K., New model for the hygrothermal calculation of condensate on the external building surface. Research in Building Physics and Building Engineering, Fazio, Ge, Rao, Desmarais (eds.), Taylor \& Francis Group, London, pp. 329-333, 2006.

[5] Pavlík, Z., Mihulka, J., Žumár, J. \& Černý, R., Experimental monitoring of moisture transfer across interfaces in brick masonry. Structural Faults and Repair 2010 [CD-ROM], Engineering Technics Press Edinburgh, Edinburgh, 2010.

[6] Pavlík, Z., Pavlík, J., Jiřičková, M. \& Černý, R., System for Testing the Hygrothermal Performance of Multi-Layered Building Envelopes. Journal of Thermal Envelope \& Building Science, 25(1), pp. 239-249, 2002. 